\title{
O diabético antes e após uma amputação - Conhecimento sobre pé diabético e consequências das amputações
}

\author{
The diabetic before and after an \\ amputation - Knowledge about \\ diabetic foot and the consequences \\ of amputations
}

FisiSenectus. Unochapecó Ano 2, n. 2 - Jul/Dez. 2014 p. $9-18$

\begin{abstract}
Alexandre Faraco de Oliveira . afaraco@gmail.com
Medico, Cirurgião Vascular, Mestre em Envelhecimento Humano, Professor curso de Medicina - Uniplac.
\end{abstract}

Evelise Pinto Rosa Faraco de Oliveira .eveliseletras@hotmail.com Mestre em Letras, professora curso de Letras Uniplac.

Thiago Andrade Wawginiak . thiagow@uniplac.net Médico graduado pela Universidade do Planalto Catarinense (2014)

Guilherme Valdir Baldo . baldo@unidavi.edu.br Graduado em Medicina pela UNIPLAC e, em Fisioterapia pela Associação Catarinense de Ensino. Global, Mestre em Engenharia de Produção pela Universidade Federal de Santa Catarina, UFSC.

\section{Resumo}

Introdução: Amputações de membros inferiores são uma grave complicação a que pacientes diabéticos estão expostos. Tais lesões, além de mutilantes, determinam uma redução na capacidade em realizar as atividades diárias dos pacientes. Objetivo: Investigar o conhecimento dos pacientes a respeito do pé diabético, o impacto das amputações sobre as atividades diárias e as percepções dos pacientes sobre essas limitações. Metodologia: 0 estudo foi feito de forma qualitativa, a partir da análise do conteúdo de entrevistas semiestruturadas. Foram entrevistados nove pacientes diabéticos, com história de ulceração seguida de amputação. Resultados e discussão: Predomina a ignorância a respeito da natureza do diabetes e suas complicações. As amputações determinaram prejuízos nas atividades diárias dos pacientes e na sua interação social, gerando dependência e sentimentos negativos. O desconhecimento dos riscos relacionados ao pé diabético implicou na ausência de medidas profiláticas. Uma vez amputado, o paciente não conseguiu recuperar o estilo de vida anterior.

\section{Palavras-chave}

pé diabético, educação em saúde, qualidade de vida, amputação, complicações do diabetes.

\section{Fisi'Senectus}




\begin{abstract}
The amputations in the lower members are the feared complications in diabetic patients. Such wounds beyond mutilation, determines reduction of the capacity on the patients daily activities. The objetive of this work is the investigation about the knowledge that patients have to the diabetic foot ulcer, and the impact of the amputations in their daily activities, like as well as the perceptions of the patients about these limitations. The study happened in a qualitative perspective, utilizing semi-structured interviews. There were nine patients interviewed with diabetic, that presented history of ulceration and amputation. The predominant ignorance prevails about the nature of diabetes and its complications. The amputations determined damage during patients daily activities, injuring their social interaction, occurring dependence and negative feelings. The unfamiliarity of the risks related to diabetic foot, implied in the absence of any prophylactic care. Once amputated the patient did not obtain recuperation of their previous lifestyle.
\end{abstract}

\title{
Keywords
}

diabetic foot, health education, quality of life, amputation, diabetes complications.

\section{Introdução}

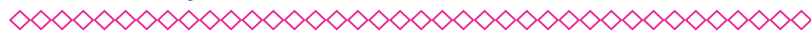

Os pacientes diabéticos apresentam uma série de alterações metabólicas, vasculares e neuropáticas que favorecem o surgimento de uma complicação bastante comum, o pé diabético ${ }^{1}$. 0 desenvolvimento de lesões e ulcerações nos pés dos diabéticos representa um grande risco para o aparecimento de infecções de difícil controle, as quais costumam exigir como parte do tratamento amputações de membros inferiores ${ }^{2}$.

A ausência de parte do seu corpo traz múltiplas consequências para o indivíduo. Em termos práticos tais consequências referem-se às limitações e restrições para desempenhar atividades da vida diária, determinando a perda da autonomia e o afastamento do trabalho por vezes definitivo. Já em termos emocionais podemos mencionar a dependência de outras pessoas em graus diversos e a consciência de estar permanentemente sujeito a novas lesões, provocadas pela mesma doença ${ }^{3,4}$.

A compreensão da dimensão do problema e das diversas formas de atuar para minimiza-lo tende a ganhar importância progressivamente nos próximos anos, tendo em vista que o diabetes tipo II torna-se mais prevalente com o envelhecimento. Estando as ulcerações relacionadas às neuropatias e estas ao tempo de diabetes, os idosos tornam-se mais susceptíveis a essas lesões ${ }^{5,6}$. Soma-se a isto o fato de que o paciente idoso tende a desenvolver limitações à medida que envelhece, a quais se somará aquela limitação causada por uma amputaçã $0^{7,8}$. Isto acontece no quadro atual de mudança demográfica, onde há o aumento proporcional do número de idosos acontecendo a cada ano ${ }^{9}$.

Este estudo buscou investigar o conhecimento dos pacientes a respeito do pé diabético, o impacto das amputações sobre as atividades diárias e as percepções dos pacientes sobre essas limitações.

\section{Materiais e métodos}

$\infty \times \infty \times \infty \times \infty \times \infty \times \infty \times \infty \times \infty \times \infty \times \infty \times \infty \times \infty \infty$

\section{Proposta de Estudo}

A pesquisa foi desenvolvida de forma qualitativa, por meio da técnica de análise de conteúdo proposta por Bardin ${ }^{10}$. A análise de conteúdo pode ser aplicada a praticamente todas as formas de comunicação, objetivando expor mensagens contidas no discurso e que não estão, necessariamente, aparentes ou explícitas, o que mantém o rigor científico da pesquisa e evita, portanto, o saber subjetivo associado a projeções pessoais. Dessa forma, o método tem que atender o desejo de rigor e a busca pela descoberta ${ }^{10}$.

Nesse processo podemos utilizar procedimentos sistemáticos e objetivos que proporcionem a identificação de categorias 
ou unidades de codificação que irão orientar o trabalho de descrição, interpretação e inferência dos conteúdos do discurso. Ao fazer uma análise de conteúdo buscamos uma correspondência de estruturas linguísticas e semânticas com estruturas psicológicas ou sociológicas.

\section{População de estudo e amostra}

A população estudada foi composta por pacientes diabéticos acometidos por lesões plantares que foram submetidos a tratamento com procedimentos cirúrgicos tipo amputação: menores (pododáctilos) ou maiores (coxa ou perna). Buscamos investigar o impacto dessas amputações em diferentes aspectos da vida dessas pessoas, em especial, mudanças que se referem a sua vida pessoal, familiar, social e laboral.

Para tanto foram realizadas entrevistas semiestruturadas, utilizando perguntas abertas que investigavam diversos aspectos a respeito das lesões dos pés, de forma a motivar o paciente a falar sobre as amputações. Também foram observados aspectos relacionados ao conhecimento do paciente sobre o diabetes e o pé diabético e a assistência de saúde (Tabela 1).

Para ser incluído na pesquisa, o paciente tinha que possuir uma história de lesão nos pés associada ao pé diabético e ser capaz de compreender e expor sua história e pensamentos a respeito da doença. Foram consideradas lesões associadas ao pé diabético aquelas relacionadas a um processo de ulceração, neuropatia, vasculopatia e infecção. 0 projeto foi submetido e aprovado por Comitê de Ética em Pesquisa com o número 045/12.

Realizamos uma busca junto a Unidades de Saúde da Família que possuem grupos de diabéticos a fim de localizar pacientes que se enquadrassem no perfil desejado: diabéticos submetidos a algum tipo de amputação nos pés.

A entrevista, previamente agendada pela Unidade de Saúde, foi realizada no domicílio do paciente, onde, após uma exposição sobre a natureza da pesquisa, foi solicitada a autorização através de Termo de Consentimento Livre e Esclarecido (TCLE). Dois estudantes do quarto ano de medicina foram treinados para realizar a entrevista, para tanto utilizaram um gravador e realizaram a transcrição dos diálogos no mesmo dia da entrevista.

\section{Pré análise}

Para realizar a pesquisa proposta, antes da análise propriamente dita, há uma fase de pré-análise, que se deu, inicialmente, pela escolha dos dados a serem analisados. Optou-se, então, pela utilização apenas das entrevistas, obedecendo à regra da exaustividade. Esses dados, as entrevistas, foram então submetidos a uma leitura "flutuante", a qual consiste em um primeiro contato com o material na expectativa de que o pesquisador seja "invadido" pelas emoções e impressões produzidas pelo material a ponto de propor hipóteses, ou seja, supor que determinadas situações são verdadeiras e estabelecer o que pode ser comprovado ou não a partir da coleta subsequente de mais dados, ou seja, as demais entrevistas.

Em nossa revisão de literatura encontramos pesquisas que permitiam supor como uma hipótese plausível que as amputações promovem mudanças nos hábitos de vida dos pacientes. Carecendo de maiores informações a respeito do tipo e da magnitude dessas mudanças e do espectro de influência no que refere à vida pessoal, social, familiar e laboral, especialmente na realidade de nossa sociedade ${ }^{11,12}$.

A preparação do material para análise consistiu na transcrição, sem que houvesse edição das gravações, mantendo, portanto, índices retidos (como pausas na fala, risos, sons incoerentes, interrupções da fala) que supõem manifestações de emoções diversas.

\section{Análise}

A análise inicia-se com o recorte, a escolha das unidades a serem utilizadas. Ao utilizar a análise temática, objetiva-se encontrar "núcleos de sentido" que dão significação ao discurso. Em nossa pesquisa, assim como em outras, procura-se observar motivações e opiniões a partir de entrevistas abertas, e a análise por temas mostrou-se como a mais adequada do que o uso apenas de palavras. 0 recorte objetiva, portanto, selecionar as unidades de contexto que mostrem a visão ou a 
opinião do sujeito (paciente) a respeito do objeto de pesquisa ${ }^{10}$.

Devemos estar atentos não apenas ao conteúdo da mensagem, mas também ao contexto associado a produção dessa mensagem. Quem estava falando, para quem e em que condições? Haviam outras circunstâncias associadas? A característica fundamental nesse tipo de pesquisa será a inferência sobre os dados apurados.

Após o recorte foi realizada a operação de categorização, na qual utilizamos categorias semânticas que surgiram da leitura flutuante e agrupamos os recortes na medida em que foram sendo encontrados. A criação de categorias buscou seguir a princípios desejáveis, como: a exclusão mútua (um elemento só poderá participar de uma categoria), a homogeneidade (entre os elementos de uma mesma categoria), a pertinência (estar relacionado ao objetivo da pesquisa), a objetividade e a fidelidade (evitar distorções e manter o padrão de categorização) e a produtividade (trazer resultados).

\section{Inferência}

A proposta da análise de conteúdo é trazer informações adicionais ao leitor, saber mais sobre o texto que está explícito. Para tanto é preciso a compreensão de que existe uma mensagem com códigos e significações, a qual parte de um emissor específico e, em determinada medida, poderá representa-lo. Por conseguinte essa mensagem será dirigida a um receptor, possivelmente para atuar sobre ou se adaptar a ele.

Aceita-se que a análise de conteúdo constitui um bom instrumento de indução para a investigação das causas a partir dos efeitos, o que, nesta pesquisa, está nas percepções geradas a partir de amputações em um contexto específico da doença relacionada ao diabetes.

\section{Resultados}

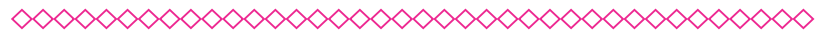

Cada paciente foi entrevistado uma única vez, sendo, ao todo, realizadas nove entrevistas que tiveram duração de 60 a 100 minutos e foram gravadas em áudio e posteriormente transcritas. To- dos os pacientes apresentavam diabetes tipo II, com faixa etária que variou dos 52 aos 79 anos. Predomínio do sexo feminino (seis mulheres e três homens), todos com o diagnóstico de diabetes há mais de dez anos. Três pacientes apresentavam amputações maiores, sendo uma amputação de perna e duas amputações de coxa. Seis apresentavam amputações menores, que variaram de dois a cinco pododáctilos. 0 momento em que se deu 0 tratamento das lesões variou de 16 meses até quatro meses antes da entrevista. Diferentes médicos, 15 profissionais, de diferentes especialidades, atuaram no tratamento dos pacientes. Após a análise os seguintes temas se apresentaram.

\section{Diabetes e sintomas neuropáticos}

O conhecimento sobre a doença diabetes se mostrou bastante restrito, há repetição de informações e, aparentemente, não há a construção de um entendimento pessoal por parte dos pacientes. Embora os pacientes não tenham demonstrado a compreensão ou o conhecimento formal do que sejam sintomas neuropáticos, repetidamente, relataram queixas compatíveis com a neuropatia periférica do diabético, com diversas apresentações, sem caracterizar a relação dessas queixas com a doença diabetes.

.ele queimava eu só tinha uma queimação nós pés assim que Deus o livre, parecia que tava pegando fogo! E doía, né... O.

Ainda que a intensidade e a frequência dos sintomas tenham variado, estes apresentam-se de forma intensa, fazendo com que os pacientes busquem diversas medidas de minimizar os sintomas.

... comecei a sentir muito queimor na sola dos pés. Eu ia dormir, tinha que ligar o ventilador porque queimava demais, sabe! Aquele desconforto... F.

A existência de alguma lesão de pele ou ulceração sem uma manifestação dolorosa associada não parece ser percebida como uma anormalidade, ou pelo menos não é vista como algo que mereça uma atenção especial.

... porque não me doía e nem nada e de repente já me deu aquela suadera... antes de me levarem para o hospital. AM. 
É que ele é todo amortecido, né... eu não sinto o pé. .

Quando eu olhei assim o dedo véio tava com uma bolha, aí pensei: Meu Deus queimei meu dedo. E não senti nada... N.

Os pacientes, espontaneamente e por vezes, foram capazes de identificar alterações produzidas pela doença, ainda que sem conectar tais alterações a possíveis consequências do diabetes.

... é que eu tenho a pele seca né. $A B$.

\section{Profilaxia do pé diabético}

Não constatamos conhecimento a respeito de práticas de prevenção a complicações da doença ou da busca de medidas preventivas no sentido de evitar possiveis lesões. De forma contrária, verificamos a exposição contínua a riscos desnecessários, que pode ser justificada por certa ingenuidade dos pacientes.

...começou no dedo grande, eu tava numa chácara aqui bem perto... e gosto de andar com os pé na geada. Então cheguei com os calçado e bota de borracha e me cai um tijolo quente no pé. Eu não sei se foi do queimado que começou ou da batida. AM.

Somado ao desconhecimento da neuropatia diabética, aparece uma abordagem inadequada frente a lesões eventuais, e um aparente desconhecimento sobre como proceder diante de uma lesão qualquer.

Saiu uma bolha d'água no pé, fez um buraquinho assim... daí eu peguei e tirei com o alicate o resto. SS.

... achei que tinha pego um bicho de pé, começou a me dar coceira, achei que era bicho de pé. Peguei uma agulha e comecei a mexer e futucando tirei demais... foi quase metade do dedo... aí passou pro outro dedo, aí mexi no outro dedo. $V$.

Quando foi um dia eu tava beliscando as pelezinha saiu um buraquinho e por ali começou. Tipo um buraco dum preguinho e eu botava remédio e remédio e não melhorava. Fui deixando... AM.

... um dia o carrinho saiu de cima da calçada e eu tropecei e dei com o pé na perna do carrinho, em quatro dias juntou água embaixo da unha e catingava meu pé. S.

\section{Calçados}

0 desconhecimento a respeito da profilaxia vai se estender quanto ao uso de calçados para diabéticos. Não parece haver percepção dos pacientes quanto ao impacto que a utilização ou não de calçados e o tipo de calçado utilizado possa ter sobre os pés. Portanto, qualquer tipo de calçado ou nenhum calçado era utilizado, nenhum dos pacientes utilizava sapato para diabético previamente ou no momento das entrevistas.

... daí minha filha comprou um sapatinho pra mim daqueles de véio sabe! que é usado bem macio e tudo... 0 .

... usava um calçadinho baixo, tamanquinho. F.

... era um tênis bem bom, bem macio, agora tá meio gasto... B.

À medida que os sintomas neuropáticos tornam-se mais presentes, a adesão ao uso de calçados é ainda mais dificultada.

Não consigo mais usar sapato fechado faz uns dez anos já mais ou menos. Não calço mais nada, só na base do chinelinho. N.

...não tem calçado que dê certo pra andar por ai, né. S.

Para alguns pacientes a limitação não é apenas de informação, mas também de recursos e disponibilidade de calçados.

Que tipo de calçado que o senhor usava (entrevistador)?

Ah, sapatão né... sempre ia de sapato e sempre apertado. Daí um dia, não é vergonha de falar, eu olho num lixeiro um sapato. Um tênis daqueles preto, bem bom. Vou pegar esse tênis eu pensei e tava chovendo eu estava de chinelo. Calcei aquele tênis. Sabe lá se não tava ali, se não foi dali que eu peguei aquele cobreiro... AB.

\section{Conhecimento sobre o pé diabético}

Os pacientes não parecem perceber a necessidade de informações sobre a doença ou mesmo a natureza da cronicidade e os riscos de evoluções desfavoráveis, como as complicações do diabetes. Tão pouco enxergam onde, como e quem deveria fornecer tais informações. 
Para falar a verdade até hoje nenhum médico conversou direito comigo sobre isso. $B$.

Embora todos tenham passado por tratamento hospitalar e, de forma unânime, relatarem a experiência como desagradável, não há o reconhecimento da condição de paciente que está sujeito que ocorram os mesmos eventos novamente. 0 que é notado na persistência de hábitos anteriores às lesões e que originaram as amputações.

E depois desse problema no pé o senhor mudou o cuidado que tem com o outro pé (entrevistador) ?

Não, cuido igual. V.

E que tipo de cuidado o senhor toma com esse pé (entrevistador)?

É só não bater e tomar os remédios. S.

\section{Amputações}

As incapacidades tornam-se maiores de acordo com o tipo de amputação. Para amputações menores houve a perda da atividade laboral, determinando redução da renda familiar e outras consequências, como a dificuldade para se locomover, restringindo a independência e confinando o paciente na própria casa.

Mudou bastante né, a gente trabalhando né, recebe aquele dinheirinho no fim do mês que hoje faz falta... B.

Ahhh eu gostaria de ser como era antes... de trabalhar, sair mais, se eu pudesse agora eu só fico mais em casa. $F$.

...as vezes lavo a louça, não trabalho mais na lavoura porque não tenho força, não tenho força nem para caminhar. SS.

Não dá pra sair... perdi o equilíbrio. S.

Para aqueles submetidos a amputações maiores evidenciou-se grande dependência dos familiares para a maioria de suas atividades e limitação para o desempenho de cuidados pessoais. Associados a essas reflexões surgiram, também, sentimentos de desânimo e frustração.

Não faço mais nada, nada mesmo. Com a cadeira de rodas não posso chegar perto do fogão, nem limpar a casa... N.

Mas agora, agora tô indo, (pausa) não me conformo da minha perna. 0 .
Ter perdido a perna pra mim foi um terror, não é fácil, ninguém queira. Porque olha faz uma falta, eu vivo presa aqui dentro dessa casa. Eu quero fazer as coisas eu não posso. Óie, é um sacrifício! Tô vivendo assim, só Deus sabe. 0 .

\section{Sentimentos frente às amputações}

Inicialmente os pacientes não costumam manifestar sentimentos de frustração ou desânimo frente às amputações, mas se questionados sobre o impacto em suas vidas e alterações decorrentes destas, tais sentimentos aparecem em diferentes aspectos.

Não pude trabalhar mais né. Daí me deu essa diabetes, tomo remédio pra diabetes, tomo remédio pra pressão... Seguido eu dou uma saidinha aí e acabo caindo, muita dor de cabeça, tontura, saio de casa com medo, já tiveram que me trazer de arrasto pra casa. $A B$.

Parece haver o reconhecimento de uma condição de desabilitado, contrastando com os períodos de vividos antes do aparecimento das lesões.

Então, quero que o senhor conte para mim o que mudou na sua vida (entrevistador).

Ah! Mudou bastante. Primeiro caminhava, saia pra fora e agora não posso mais nem sair... Mudou, mudou, de 100 voltou para zero. $V$.

Ah mudou sim, muito. O meu serviço toda a vida foi serviço de pedreiro, e depois dessa aí, dai tive que abandonar né se aquietar e ficar quieto. AM.

Ah meu senhor! Me deu muita fraqueza e perdi a possibilidade de homem perdi a potência... SS.

... eu não posso fazer mais nada, não posso caminhar... não caminho sozinho. Alguém tem que ajudar, né... N.

Eu sou inútil mesmo. 0.

O meu sonho é que eu pudesse voltar a trabalhar. E vou ainda, se Deus quiser eu vou... SS.

\section{Discussão}

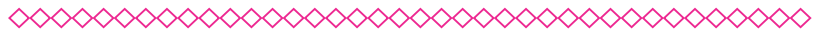

No que tange ao conhecimento da doença, diabetes mellitus e principalmente dos riscos de complicações nos pés, a amostra apresentou-se da mesma forma que em outros estudos ${ }^{1,13}$ que já de- 
monstravam um predomínio de desconhecimento do tema. Esse quadro conduz a hábitos inadequados para o diabético colocando-o em risco constante. Quanto maior o tempo de diabetes, maiores as chances de desenvolvimento de complicações como a neuropatia periférica e, consequentemente, as possibilidades de lesão se multiplicam ${ }^{12,14-16}$.

Fatalmente parte dessas lesões levará a amputações e então esses pacientes estarão condenados às consequências danosas originadas a partir dessas mutilações. Além do impacto social e econômico a própria morbimortalidade aumenta significativamente após uma amputação ${ }^{17,18}$.

A condição de doença crônica do diabetes e de suas complicações, como o pé diabético, impõem aos pacientes mudanças nos hábitos de vida. Associadas ao temor da evolução desfavorável da doença e o medo constante de novas mutilações, essa situação costuma gerar desânimo e desesperança, e os pacientes, por vezes, procuram compensar tais sentimentos apoiando-se ao que estiver à sua disposição, seja a unidade de saúde, os familiares, a fé religiosa ou os amigos ${ }^{3,8}$.

0 impacto do aparecimento de alterações psicológicas como a depressão e a ansiedade pode se estender para outras esferas, inclusive contribuindo para retardar a cicatrização das lesões existentes e favorecer o aparecimento de novas ulcerações, alimentado o círculo vicioso de ulceração, depressão e nova ulceração sucessivamente ${ }^{3,14}$.

Todos os pacientes relataram ter o suporte adequado da Unidade Básica de Saúde (UBS), o que, considerando as propostas do Sistema Único de Saúde (SUS), compreende que o serviço de atenção primária informe e eduque a população a respeito de necessidades básicas de saúde de forma geral e, em situações específicas como o diabetes, por meio de grupos. Isto fica explícito no Caderno de Atenção Básica no. 16 destinado a Diabetes Mellitus: "O cuidado integral ao paciente com diabetes e sua família é um desafio para a equipe de saúde, especialmente para poder ajudar o paciente a mudar seu modo de viver, o que estará diretamente ligado à vida de seus familiares e amigos. Aos poucos, ele deverá aprender a gerenciar sua vida com diabetes em um processo que vise qualidade de vida e autonomia ${ }^{19 "}$.
A pesquisa não visava e, portanto, não permite determinar se as UBS estão atuando da maneira educativa a qual se pretende, porém, claramente o nível de conhecimento sobre a doença por parte dos pacientes é mínimo. Assim, caso o trabalho educacional tenha sido realizado, este não atingiu o objetivo de proporcionar aos pacientes a compreensão de sua doença.

É importante lembrar que todos os pacientes estiveram em ambiente hospitalar e se o tratamento foi ofertado de forma adequada, também houve a oportunidade de informar e educar os pacientes e familiares, o que leva a crer que tal oportunidade não foi aproveitada ou não atingiu o objetivo de conscientizar sobre a doença.

No paciente diabético uma ulceração plantar deve ser entendida como um desequilíbrio da doença, portanto, uma situação em que a atenção e os cuidados devem ser intensivos. 0 paciente passará a ter aumentado significativamente os riscos de novas ulcerações, infecções e amputações ${ }^{6}$.

0 tratamento e a prevenção do pé diabético estão fundamentalmente ligados a educação do paciente, conhecimento sobre a doença e na utilização de calçados especiais para a proteção dos pés. Como regra, o tratamento do pé diabético costuma acarretar a perda de parte dos pés, portanto, os esforços devem ser dirigidos à profilaxia como forma mais efetiva de prevenir as amputações e suas consequências ${ }^{20,21}$.

Em um estudo com delineamento qualitativo devemos ter especial atenção a fim de evitar o risco de opiniões subjetivas, que não se sustentem no método utilizado, representando opiniões e preconceitos. Na intenção de superar tais limitações, buscamos o rigor metodológico e revisões individualizadas para a correção de supostos desvios.

Por suas características a pesquisa qualitativa exige um laborioso trabalho de coleta de dados, o qual costuma restringir o número de indivíduos e em troca oferece maior qualidade do material coletado. Nesta pesquisa entendemos que a amostra seja pequena, porém adequada para a obtenção de material suficiente para a produção do conhecimento científico a que se propõe. 


\section{Considerações finais}

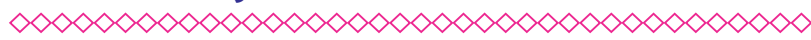

Como ocorre em muitas doenças, o pé diabético é uma evolução desfavorável, porém previsível de outra moléstia. Também como em outras enfermidades, a prevenção necessita de especial atenção, pois uma vez estabelecida a doença, dificilmente será tratada sem que ajam mutilações permanentes, por vezes incapacitantes.

Sendo o diabetes e, portanto, o pé diabético, diretamente associados ao envelhecimento, a expectativa atual é de que juntamente com o progressivo aumento da população idosa, que ocorre no Brasil e no mundo, ocorra o aumento do número de pacientes sujeitos as lesões do pé diabético.

A cada dia aumenta o contingente de pessoas, principalmente idosos, que demandam a oferta de serviços de profilaxia. Tal prevenção é fundamental para tenhamos um envelhecimento ativo, ou seja, um cidadão que possa participar ativamente de questões cívicas, econômicas, culturais, espirituais e tantas outras que deseje. Para tanto é necessária atenção à disponibilidade de conhecimento e recursos para a vida longa e saudável.

\section{Referências}

$\infty \times \infty \times \infty \times \infty \times \infty \times \infty \times \infty \times \infty \times \infty \times \infty \times \infty \times \infty \times \infty$

1. Diretrizes da Sociedade Brasileira de Diabetes/ Sociedade Brasileira de Diabetes. $3^{\mathrm{a}}$.ed. Itapevi, SP: A. Araujo Silva Farmaceutica, 2009. p129-143.

2. Hobizal KB, Wukich DK. Diabetic foot infections: current concept review. Diabetic foot \& ankle. 2012;1:1-8.

3. Beattie AM, Campbell R, Vedhara K. 'What ever I do it's a lost cause.' The emotional and behavioural experiences of individuals who are ulcer free living with the threat of developing further diabetic foot ulcers: a qualitative interview study. Health Expect. 2012 Mar 20.

4. Batista F, Augusto Magalhães A, Gamba M, Nery C, Cardoso $C$. Ten years of a multidisciplinary diabetic foot team approach in Sao Paulo, Brazil. Diabetic foot \& ankle. 2010 Jan;1:1-3.
5. Kesavadev JD, Short KR, Nair KS. Diabetes in old age: an emerging epidemic. The Journal of the Association of Physicians of India. 2003;51:1083-94.

6. Apelqvist J. The foot in perspective. Diabetes Metab Res Rev. 2008 May-Jun;24 Suppl 1:S110-5.

7. Parahyba, MI; Simões, CCS. A prevalência de incapacidade funcional em idosos no Brasil. Ciênc. saúde coletiva. 2006;11:4:967-974.

8. Souza, NMG; et al. Visão do mundo, cuidado cultural e conceito ambiental: o cuidado do idoso com diabetes Mellitus. Rev. Gaúcha Enferm. 2012;33:1:139-146

9. Brasil. Ministériodo Planejamento, Orçamento e Gestão. Instituto Brasileiro de geografia e Estatística. Projeção de População do Brasil por sexo para o período 1980-2050. Revisão 2004. Disponível em <http://www.ibge.gov.br>.

10. Bardin L. Análise de Conteúdo. 1a.edição ed São Paulo - Brasil: Edições 70 - Almedina Brasil; 2011. p. 01-280.

\section{Ritholz MD, Beverly E, Weinger K. Digging} deeper: the role of qualitative research in behavioral diabetes. Current diabetes reports. 2011;11:6:494-502

12. Gale L, Vedhara K, Searle A, Kemple T, Campbell R. Patients' perspectives on foot complications in type 2 diabetes: a qualitative study. The British journal of general practice : the journal of the Royal College of General Practitioners. 2008;58:555-63.

13. Laurindo MC, Recco DC, Roberti DB, Rodrigues CDS. Conhecimento das pessoas diabéticas acerca dos cuidados com os pés Diabetic Patients ' Knowledge about foot care. Arquivos de Ciências da Saúde. 2005;12:2:80-4.

14. Vedhara K, Miles JNV, Wetherell M, Dawe K, Searle $a$, Tallon D. Coping style and depression influence the healing of diabetic foot ulcers: observational and mechanistic evidence. Diabetologia. 2010 Aug;53:8:1590-8.

15. Stess RM, Jensen SR, Mirmiran R. The role of dynamic plantar pressures in diabetic foot ulcers. Diabetes care. 1997;20:5:855-8. 
16. Lipsky BA, et al. Expert opinion on the management of infections in the diabetic foot. Diabetes Metab Res Rev. 2012 Feb;28 Suppl 1:16378.

17. Faglia E, Favales F, Morabito a. New ulceration, new major amputation, and survival rates in diabetic subjects hospitalized for foot ulceration from 1990 to 1993: a 6.5-year follow-up. Diabetes care. $2001 ; 24: 1: 78-83$.

18. Herber OR, Schnepp W, Rieger M a. A systematic review on the impact of leg ulceration on patients' quality of life. Health and quality of life outcomes. 2007 Jan; 5:44.

19. Brasil. Ministério da Saúde - Cadernos de Atenção Básica - n.o 16- Diabetes Mellitus. Ministério da Saúde, editor. Brasilia - DF; 2006. p. 1-56.

20. Al-Wahbi AM. Impact of a diabetic foot care education program on lower limb amputation rate. Vascular health and risk management. 2010 Jan;6:923-34.

21. Lavery LA, Hunt NA, Lafontaine J, Baxter CL, Ndip A, Boulton AJ. Diabetic foot prevention: a neglected opportunity in high-risk patients. Diabetes Care. 2010 Jul;33, 7:1460-2. 


\section{Anexos}

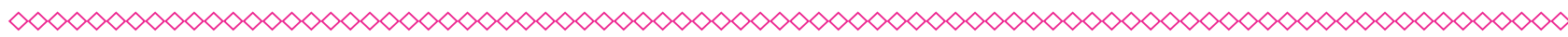

Tabela 1: Tópicos abordados na entrevista aplicada ao paciente

\section{Identificação: Nome, gênero, idade, tempo de diabetes, medicações em uso}

Conhecimento sobre diabetes e pé diabético.

- "O que o(a) senhor(a) sabe sobre o diabetes?"

-"Qual os cuidados com os pés que você tinha antes de se machucar?"

- "E agora, quais cuidados tem com os pés?"

Questões a respeito das lesões dos pés

- "Me diga como aconteceu a lesão em seu pé?"

Assistência primária à saúde

- "Você teve alguma orientação sobre cuidados com os pés?";

- "O pessoal da Unidade de Saúde presta alguma ajuda ao(a) senhor(a) ?"

Investigação a respeito de mudanças advindas da amputação

- "O que mudou para você após as amputações nos pés?"

- "Tinha alguma coisa que você fazia antes e não faz agora?"

Fonte: Dados da pesquisa.

(clique para voltar ao texto) 